\title{
Interneuronal Network Activity at the Onset of Seizure-Like Events in Entorhinal Cortex Slices
}

\author{
느aura Librizzi, ${ }^{1 *}$ (CGabriele Losi, ${ }^{3,4 \star}$ Iacopo Marcon, ${ }^{3,4}$ Michele Sessolo, ${ }^{3,4}$ PPaolo Scalmani, ${ }^{2}$ \\ (1) Giorgio Carmignoto, ${ }^{3,4}$ and Marco de Curtis ${ }^{1}$ \\ Units of ${ }^{1}$ Epileptology and ${ }^{2}$ Clinical Neurophysiology, Fondazione Istituto Neurologico Carlo Besta, 20133 Milano, Italy, and ${ }^{3}$ Neuroscience Institute, \\ National Research Council and ${ }^{4}$ Department of Biomedical Sciences, University of Padova, 35121 Padova, Italy
}

The onset of focal seizures in humans and in different animal models of focal epilepsy correlates with reduction of neuronal firing and enhanced interneuronal network activity. Whether this phenomenon contributes to seizure generation is still unclear. We used the in vitro entorhinal cortex slices bathed in 4-aminopirydine (4-AP) as an experimental paradigm model to evaluate the correlation between interneuronal GABAergic network activity and seizure-like events. Epileptiform discharges were recorded in layer V-VI pyramidal neurons and fast-spiking interneurons in slices from male and female mice and in the isolated female guinea pig brain preparation during perfusion with 4 -AP. We observed that $90 \%$ of seizure-like events recorded in principal cells were preceded by outward currents coupled with extracellular potassium shifts, abolished by pharmacological blockade of $\mathrm{GABA}_{\mathrm{A}}$ receptors. Potassium elevations associated to $\mathrm{GABA}_{\mathrm{A}}$ receptor-mediated population events were confirmed in the entorhinal cortex of the in vitro isolated whole guinea pig brain. Fast-rising and sustained extracellular potassium increases associated to interneuronal network activity consistently preceded the initiation of seizure-like events. We conclude that in the 4-AP seizure model, interneuronal network activity occurs before 4-AP-induced seizures and therefore supports a role of interneuron activity in focal seizure generation.

Key words: 4-aminopyridine; extracellular potassium; GABAergic interneuronal network

\section{Significance Statement}

The paper focuses on the mechanisms of ictogenesis, a topic that requires a step beyond the simplistic view that seizures, and epilepsy, are due to an increase of excitatory network activity. Focal temporal lobe seizures in humans and in several experimental epilepsies likely correlate with a prevalent activation of interneurons. The potassium channel blocker 4-aminopyridine reliably induces seizure-like events in temporal lobe structures. Herein, we show that a majority of seizures in the entorhinal cortex starts with interneuronal network activity accompanied by a fast and sustained increase in extracellular potassium. Our new findings reinforce and add a new piece of evidence to the proposal that limbic seizures can be supported by GABAergic hyperactivity.

\section{Introduction}

Presurgical exploration with intracranial electrodes in patients with drug-resistant focal epilepsy showed that seizures in neocortical and mesial temporal epileptogenic areas initiate with a decrease of single unit activity (Truccolo et al., 2011; Weiss et al., 2013, 2016). These findings suggest that focal seizures start with a marked reduc-

Received Dec. 21, 2016; revised July 5, 2017; accepted July 8, 2017.

Author contributions: L.L., G.L., G.C., and M.d.C. designed research; L.L., G.L., I.M., M.S., and P.S. performed research; L.L. and G.L. analyzed data; L.L., G.L., G.C., and M.d.C. wrote the paper.

This work was supported by Telethon Italy Grant GGP12265, the Cariparo Foundation, the National Research Council Aging Project, Fondo per gli Investimenti della Ricerca di Base Grant RBAP11X42L, ERANET-NEURONJTC2014 BriE ANR-14-NEUR-0004, and the Italian Health Ministry (Finanziamento di Ricerca Corrente 2012-2016).

*L.L. and G.L. contributed equally to this work.

The authors declare no competing financial interests.

Correspondence should be addressed to Dr. Laura Librizzi, Laboratory of Neurophysiology, Unit of Epileptology, Fondazione Istituto Neurologico Carlo Besta, via Celoria 11, 20133 Milano, Italy. E-mail: laura.librizzi@istituto-besta.it.

DOI:10.1523/JNEUROSCI.3906-16.2017

Copyright $\odot 2017$ the authors $\quad 0270-6474 / 17 / 3710398-10 \$ 15.00 / 0$ tion of neuronal activity. Moreover, focal seizure-like events induced by different pharmacological and functional manipulations in acute in vitro models are heralded by interneuronal network activity coupled with dampening of principal cell firing (Lopantsev and Avoli, 1998; Fujiwara-Tsukamoto et al., 2006, 2010; Ziburkus et al., 2006; Derchansky et al., 2008; Gnatkovsky et al., 2008; Lasztóczi et al., 2009; Imamura et al., 2011; Sessolo et al., 2015). Decreased principal neuron activity (Fujita et al., 2014) and increased interneuronal firing (Grasse et al., 2013; Toyoda et al., 2015) have been confirmed by single and multiunit recordings at the onset of focal hippocampal seizures in the rat pilocarpine model of mesial temporal lobe epilepsy. In addition, optogenetic stimulation of inhibitory interneurons in entorhinal cortex slices was sufficient to generate or favor seizure-like events (Sessolo et al., 2015; Shiri et al., 2015, 2016; Yekhlef et al., 2015). These findings strongly suggest the involvement of enhanced interneuronal network activity at the onset of focal seizures (de Curtis and Gnatkovsky, 2009; Avoli and de Curtis, 2011; Avoli et al., 2016; de Curtis and Avoli, 2016). 
The functional implication of enhanced GABAergic network activity ahead of a focal seizure has been interpreted either as inhibitory restraint to seizure progression and propagation (Trevelyan et al., 2007; Cammarota et al., 2013; Weiss et al., 2013; Sessolo et al., 2015; Smith and Schevon, 2016) or as a pro-ictogenic event related with seizure generation (Gnatkovsky et al., 2008; de Curtis and Gnatkovsky, 2009; Avoli and de Curtis, 2011; Sessolo et al., 2015; de Curtis and Avoli, 2016). It has been hypothesized that synchronous activation of interneuronal networks at seizure onset correlates with changes in extracellular potassium $\left(\left[\mathrm{K}^{+}\right]_{0}\right.$; Avoli et al., 1996a), and that these changes sustain the progression of a seizure (Avoli and de Curtis, 2011; Trombin et al., 2011). This hypothesis is based on the analysis of inter-ictal and pre-ictal GABAergic population events recorded in acute models of focal seizures induced by bicuculline, 4-aminopyridine (4-AP) and by lowmagnesium solutions (Avoli et al., 1996a; Boido et al., 2014; Uva et al., 2015). The increase in $\left[\mathrm{K}^{+}\right]_{\mathrm{o}}$ during GABA-mediated interictal spikes was first observed in the 4-AP model in the studies by Avoli et al., 1996a,b, which reported in entorhinal cortex in vitro slices a threshold value of $\left[\mathrm{K}^{+}\right]_{\mathrm{o}}$ at the start of the tonic phase of seizures.

To better understand the relationship between GABAergic network activity, $\left[\mathrm{K}^{+}\right]_{\mathrm{o}}$ changes and seizure-genesis, we performed in vitro experiments on entorhinal cortex mouse slices bathed in 4-AP and on the in vitro isolated guinea pig brain. We use 4-AP in model as an experimental paradigm to reliably generate recurrent GABAergic population events (Avoli et al., 1996a; Uva et al., 2009) at a rate that consents a quantified neurophysiological analysis. We demonstrate that interneuronal network activation per se correlates with events that evolve into a seizurelike event (SLE). The findings were presented in abstract form at the XII European Congress on Epileptology in Prague (Librizzi et al., 2016).

\section{Materials and Methods}

Animals. The number of animals used for the study was minimized according to the International guidelines on ethical use of animals [European Communities Council Directive of 24 November 1986 (86/109/ EEC)]. The experimental protocol was reviewed and approved by the National Council on Animal Care of the Italian Ministry of Health.

Slice preparation. Experiments were performed on temporal lobe slices obtained from 15 young adult C57BL6J mice (postnatal day15-19) of both sexes. Coronal slices that include the medial entorhinal cortex (mEC) were prepared from 15 mice. Briefly, animals were deeply anesthetized with intraperitoneal-injected Zoletil $(40 \mathrm{mg} / \mathrm{kg})$ and were decapitated; the brain was quickly removed and transferred to ice-cold standard solution containing the following (in mM): $125 \mathrm{NaCl}, 2.5 \mathrm{KCl}, 2$ $\mathrm{CaCl}_{2}, 1 \mathrm{MgCl}_{2}, 25$ glucose, maintained at $\mathrm{pH} 7.4$, with $5 \% \mathrm{CO}_{2} / 95 \% \mathrm{O}_{2}$. After brain dissection, $350-\mu \mathrm{m}$-thick slices were cut in the coronal plane with a vibratome (VT1000S, Leica Microsystems) as previously described (Dugué et al., 2005). Slices were transferred for $1 \mathrm{~min}$ in a $5 \% \mathrm{CO}_{2} / 95 \%$ $\mathrm{O}_{2}$ saturated solution containing the following (in mM) 225 D-mannitol, $2.5 \mathrm{KCl}, 1.25 \mathrm{NaH}_{2} \mathrm{PO}_{4}, 26 \mathrm{NaHCO}_{3}, 25$ glucose, $0.8 \mathrm{CaCl}_{2}, 8 \mathrm{MgCl}_{2}$, and 2 kynurenic acid and then were finally transferred in standard perfusion solution at $30^{\circ} \mathrm{C}$ for $20 \mathrm{~min}$ maintained at room temperature. mEC slices were transferred to a submerged chamber continuously perfused at a rate of $3 \mathrm{ml} / \mathrm{min}$ with a solution containing the following (in mM) $120 \mathrm{NaCl}$, $2.5 \mathrm{KCl}, 1 \mathrm{KH}_{2} \mathrm{PO}_{4}, 26 \mathrm{NaHCO}_{3}, 0.5 \mathrm{MgCl}_{2}, 2 \mathrm{CaCl}_{2}, 10$ glucose, pH 7.4 $\left(5 \% \mathrm{CO}_{2} / 95 \% \mathrm{O}_{2}\right)$. Single- and dual-cell recordings were performed in current-clamp and voltage-clamp configurations using a multiclamp700B amplifier (Molecular Devices). Signals recorded with a Digidata 1440s interface and pClamp10.5 software (Molecular Devices) were sampled at $10 \mathrm{kHz}$ and filtered at $1 \mathrm{kHz}$. Whole-cell intracellular pipette solution contained the following (in $\mathrm{mM}$ ): $145 \mathrm{~K}$-gluconate, $4 \mathrm{MgCl}_{2}, 0.5$ EGTA, $2 \mathrm{Na}_{2} \mathrm{ATP}, 0.2 \mathrm{Na}_{2}$ GTP, 10 HEPES, pH 7.2 with $\mathrm{KOH}$; osmolarity was 305-315 mOsm. Typical pipette resistance was 3-4 M $\Omega$. Access resistance monitored throughout the recordings was typically $<25 \mathrm{M} \Omega$. Data were not corrected for the liquid junction potential (calculated liquid junction potential: $-14 \mathrm{mV}$ ). Pyramidal neurons (PyrNs; $n=18$ ) were identified under microscopic control with a $20 \times$ objective and a $4 \times$ digital zoom on a TCS-SP5-RS microscope (Leica Microsystems) on the basis of their distinct morphology characterized by the triangular shape of the soma, a main apical dendrite pointing toward the pia and the absence of a main dendrite in the opposite direction. Their biophysical identity was confirmed by their response to hyperpolarizing and depolarizing $750 \mathrm{~ms}$ current steps. Regular spiking PyrNs showed a firing discharge with no spike amplitude accommodation (except for the second action potential in some cells), small afterhyperpolarization, and low steady-state frequency (15-23 Hz with 200 pA current injection). Fast spiking interneurons (FS-INs; $n=5$ ) were identified by their small round soma and two main dendrites emerging in opposite directions and were confirmed by response to current steps evoking high steady-state firing frequency (50-90 Hz with $400 \mathrm{pA}$ current injection), no spike amplitude accommodation nor frequency adaptation and large afterhyperpolarizations. Access resistance was monitored throughout the experiments. All patched neurons were from mEC layers V-VI. All PyrNs were voltageclamped at $-50 \mathrm{mV}$. The correlation between IPSCs recorded in PyrNs and FS-INs firing activity was evaluated by calculating the coefficient of linear regression between PyrN IPSCs and FS-IN EPSPs areas (with action potentials) for each pair of cells. All inter-ictal-IPSCs (iiIPSCs) and pre-ictal-IPSCs ( $\pi$-IPSCs) from six pair recordings were pooled in two groups and R2 was calculated. SLEs were induced by a standard solution containing 4-AP (100 $\mu \mathrm{M}$; Sigma-Aldrich) and low $\mathrm{Mg}^{2+}(0.25-0.5 \mathrm{~mm})$.

NMDA and AMPA glutamate receptors blockers D-(-)-2-amino-5phosphonopentanoic acid (APV; $50 \mu \mathrm{M}$; Tocris Bioscience) and 2,3dioxo-6-nitro-1,2,3,4-tetrahydrobenzo[f] quinoxaline-7-sulfonamide (NBQX; $10 \mu \mathrm{M}$; Tocris Bioscience) were dissolved in the standard solution. Bath temperature was maintained at $30^{\circ} \mathrm{C}$ by an in line solution heater and temperature controller (TC-324B, Warner Instruments).

Isolated guinea pig brain preparation. Experiments were performed on five adult Hartley female guinea pig (150-200 g) brains maintained in vitro by arterial perfusion. Animals were deeply anesthetized by intraperitoneal injection of sodium thiopental $(125 \mathrm{mg} / \mathrm{kg}$; Farmotal, Pharmacia). The heart was exposed and intracardiac perfusion with a cold $\left(4^{\circ} \mathrm{C}\right)$, carboxygenated $\left(95 \% \mathrm{O}_{2} / 5 \% \mathrm{CO}_{2}\right)$ solution was performed [containing (in mM ): $126 \mathrm{NaCl}, 3 \mathrm{KCl}, 1.2 \mathrm{KH}_{2} \mathrm{PO}_{4}, 1.3 \mathrm{MgSO}_{4}, 2.4 \mathrm{CaCl}_{2}, 26$ $\mathrm{NaHCO}_{3}, 15$ mm glucose, $2.1 \mathrm{~mm}$ HEPES, and 3\% dextran MW 70.000, $\mathrm{pH}$ 7.2]. After 3 min perfusion the animal was decapitated, the brain was carefully dissected out (de Curtis et al., 1991, 1998; Mühlethaler et al., 1993) and was placed in a recording chamber. A polyethylene cannula was inserted in the basilar artery to restore the perfusion with the same saline solution, $\mathrm{pH}$ 7.4. The temperature of the chamber was raised from $15^{\circ} \mathrm{C}$ to $32^{\circ} \mathrm{C}$ by steps of $0.2^{\circ} \mathrm{C} / \mathrm{min}$. Extracellular recordings in the $\mathrm{mEC}$ were simultaneously performed with glass pipettes filled with $0.9 \% \mathrm{NaCl}$ (5-10 $\mathrm{M} \Omega$ resistance) and with potassium-sensitive electrodes (described below: Fig. $7 A$ ). Signals were amplified via a multichannel differential amplifier (Supertech), were acquired unfiltered in DC at $2 \mathrm{kHz}$ and were analyzed using custom-made software (ELPHO) developed by Dr. Gnatkovsky in our laboratory. To induce epileptiform activity, the potassium channel blocker 4-AP (50 $\mu \mathrm{M}$; Tocris Bioscience) was arterially perfused for $4 \mathrm{~min}$ in the isolated whole brain. AMPA and NMDA receptor blockers NBQX (50 $\mu \mathrm{m}$; Tocris Bioscience) and AP5 (100 $\mu \mathrm{M}$; Tocris Bioscience) and the $\mathrm{GABA}_{\mathrm{A}}$ receptors antagonist bicuculline methiodide (BMI; $50 \mu \mathrm{m}$; Sigma-Aldrich) were dissolved in the perfusate and were applied via the resident arterial system.

Extracellular potassium recordings. Two-barrel, ion-selective electrodes (tip diameter 3-5 $\mu \mathrm{m}$ ) were used to record $\left[\mathrm{K}^{+}\right]_{\mathrm{o}}$ in the mEC of both in vitro preparations (Librizzi et al., 2001; Gnatkovsky et al., 2008). The conventional electrode was filled with $\mathrm{NaCl} 0.9 \%$. The barrel used to $\left[\mathrm{K}^{+}\right]_{\mathrm{o}}$ measurements was filled at the tip with the potassium ionophore I mixture A (Fluka 60031) after 1 min exposure to dimethyldichlorosylane vapors (Fluka) and was then backfilled with $0.2 \mathrm{M} \mathrm{KCl}$ following a $2 \mathrm{~h}$ incubation at $120^{\circ} \mathrm{C}$. Potassium calibration solutions had the same com- 
position of the solution used for slice perfusion, except for $\mathrm{KCl}$ concentration modified to obtain final $\mathrm{K}^{+}$concentration of $1,1.5,2,2.5,6$, and $12.5 \mathrm{~mm}$. The voltage $(\mathrm{mV})$ measured for each calibration solution was converted to $\mathrm{K}^{+}$concentration values using the formula $Y=s \log X$, where $Y$ is the voltage measured, $s$ is the slope of the calibration curve, and $X$ is the $\left[\mathrm{K}^{+}\right]_{\mathrm{o}}$ concentration. Only microelectrodes with a response of $30-40 \mathrm{mV}$ per $10 \mathrm{~mm}$ of $\mathrm{K}^{+}$were used. Ion-selective signals were amplified with a high-input impedance head-stage amplifier (Biomedical Engineering). Subtraction of the field potential from the ion-sensitive electrode voltage reading was performed automatically by the amplifier. Data were acquired by the same software used for single glass pipettes recordings.

Experimental design and statistical analysis. The study includes the analysis of (1) 112 outward and 15 inward inter-ictal events and 59 SLEs recorded in 20 cells from 15 mice, and (2) 58 inter-ictal spikes and 23 SLEs recorded from five isolated guinea pig brain preparations. Data analysis was performed with Clampfit 10.5, OriginPro 2016 (OriginLab) and Excel Microsoft Office. Quantitative results were analyzed using Student $t$ and Mann-Whitney tests. Normal distribution of samples was checked with Shapiro-Wilks test and the homogeneity of variances with $F$ test (always verified with the exception of the data on time to $\mathrm{K}^{+}$peak; Fig. $6 C$, right graph). The Mann-Whitney nonparametric test was chosen when data were not normally distributed. Otherwise, Student $t$ test was used. The format of Student $t$ test results is as follows: $t(\mathrm{df})=t$ statistic, $p=$ significance value. The format of Mann-Whitney test results is as follows: $p=$ significance value. The tests are two-sided and significance was set at $p<0.05$. Data are shown as mean \pm SD.

\section{Results}

\section{Slice preparation}

Layer V-VI PyrNs were recorded in voltage-clamp at a holding potential of $-50 \mathrm{mV}$ to provide a reasonable driving force to outward $\mathrm{GABA}_{\mathrm{A}}$-mediated IPSCs. The average IPSCs reversal potential was $-73.9 \pm 1.1 \mathrm{mV}(n=16$; corrected for the liquid junction potential of $-14.2 \mathrm{mV}$ ). This value was similar in gramicidin perforated-patch recordings that preserve internal negative charges $(-69.2 \pm 2.9 \mathrm{mV} ; n=6) .\left[\mathrm{K}^{+}\right]_{\mathrm{o}}$ measurements were simultaneously performed close to the recorded PyrNs $(<150-$ $200 \mu \mathrm{m}$ distance; Fig. $1 A$, right microphotograph). Continuous perfusion of mEC slices with $100 \mu \mathrm{M} 4$-AP and low $\mathrm{Mg}^{2+}$ solution triggered epileptiform inter-ictal discharges and SLEs that recurred every $683 \pm 338 \mathrm{~s}(n=59)$. Voltage-clamp recordings revealed the occurrence of two distinct types of SLE. In 53 of 59 SLEs recorded in 20 cells from 15 mice, ictal discharge initiated with "pre-ictal" outward ("inhibitory") postsynaptic currents $(\pi$-IPSCs; Fig. $1 B b)$. The remaining six SLEs started with pre-ictal inward (excitatory) currents ( $\pi$-EPSCs; 4 cells from 4 mice; Figs. $1 B c, C c, 2)$. Both IPSC- and EPSC-onset SLEs evolved into a phase dominated by large amplitude inward currents (Fig. $1 B$, arrowheads). The duration of IPSC- and EPSC-driven SLEs was $233 \pm$ 151 and $159 \pm 49$ s, respectively. SLEs were usually anticipated by inter-ictal and pre-ictal events largely sustained by outward currents (Figs. $1 \mathrm{Ba}, 2$, left). Incidentally, preictal-PSCs are legitimate ictal events, because they were defined by their occurrence just ahead of a SLE. As illustrated in Figures $1 B$ and $2,\left[\mathrm{~K}^{+}\right]_{\mathrm{o}}$ increases were associated to outward inter-ictal events (ii-IPSCs; 112 from 20 cells in 15 mice), to inward excitatory inter-ictal events (iiEPSCs; 15 from 3 cells in 3 mice), to pre-ictal events and to full ictal SLEs $(n=59)$. In the present paper we focused on SLEs preceded by pre-ictal IPSCs, that represented the large majority of 4-AP-induced epileptiform events (Fig. 2, right graph). ii-IPSC and $\pi$-IPSC in PyrN consistently preceded the $\left[\mathrm{K}^{+}\right]_{\mathrm{o}}$ rise by $109 \pm 59 \mathrm{~ms}$ and $117 \pm 48 \mathrm{~ms}$, respectively. We assumed that the $\left[\mathrm{K}^{+}\right]_{\mathrm{o}}$ changes recorded with the ion-selective electrode were generated by events in the proximity of the patched neuron(s) in the deep mEC layers.

Activation of FS-INs and the associated $\left[\mathrm{K}^{+}\right]_{0}$ rise precede principal cell involvement in SLE generation

Next, we investigated the involvement of FS-INs that target somata of mEC PyrN (Freund and Katona, 2007) in the generation of the ictal events and the associated $\left[\mathrm{K}^{+}\right]_{\mathrm{o}}$ changes. We performed dual cell recordings from a putative FS-IN in current-clamp configuration and from a neighboring PyrN in voltage-clamp configuration (distance between FS-IN and PyrN, 70-150 $\mu \mathrm{m} ; n=4$ cell pairs); $\left[\mathrm{K}^{+}\right]_{\mathrm{o}}$ was simultaneously measured through an ion-selective electrode positioned close to the patched neurons (Fig. 3A). From these experiments, a number of observations can be made. The spiking activity in FS-IN correlated with outward "inhibitory" currents in paired PyrN (Fig. 3 B, C). Bursts of action potentials, superimposed to a depolarization shift in FS-INs, correlated with inter-ictal-IPSCs (ii-IPSCs) and pre-ictal-IPSCs ( $\pi$-IPSCs) recorded in PyrNs during 4-AP from all pair recordings $(n=6)$. For both event types a clear linear correlation between FS-EPSPs and PyrN-IPSCs was found (Materials and Methods), the $R^{2}$ being 0.87 for ii-IPSCs $(n=21)$ and 0.98 for $\pi$-IPSCs $(n=12)$.

The pre-ictal firing activity in FS-INs also correlated with $\left[\mathrm{K}^{+}\right]_{\mathrm{o}}$ elevations (Fig. $3 B-E$, top traces). The end of the bursting phase in the FS-INs and the peak of the pre-ictal burst-associated $\left[\mathrm{K}^{+}\right]_{\mathrm{o}}$ changes coincided with the appearance of inward currents in the nearby PyrN (Fig. 3 B, C; 4 cells from 3 mice). The progression into the SLE discharge coincided with FN-IN depolarization associated with a delayed rise in $\left[\mathrm{K}^{+}\right]_{\mathrm{o}}$ (Fig. $3 B$ ) that further increased during the recruitment of the delayed large PyrN inward currents (Fig. $3 B, C$ ). As illustrated in the representative recording from a PyrN and FS-IN pair in current-clamp configuration, the bursting of FS-IN was coupled with both increased $\left[\mathrm{K}^{+}\right]_{\mathrm{o}}$ and hyperpolarizing potentials in the connected PyrN (Fig. 3D, $E ; n=4$ ). Therefore, paired recordings from adjacent putative FS-IN and PyrNs confirmed that the SLE onset was preceded and dominated by FS-IN firing and the associated elevation in $\left[\mathrm{K}^{+}\right]_{\mathrm{o}}$.

Neurotransmitter signaling involved in 4-AP-induced activity and the associated $\left[\mathrm{K}^{+}\right]_{o}$ shifts

Simultaneous voltage-clamp and $\left[\mathrm{K}^{+}\right]_{\mathrm{o}}$ recordings revealed that 4-AP-induced SLEs were blocked by coperfusion with both AMPA and NMDA glutamate receptor antagonists, NBQX $(10 \mu \mathrm{m})$ and APV (50 $\mu \mathrm{M}$; Fig. $4 B$ ). Notably, however, both inter-ictal IPSCs and the associated $\left[\mathrm{K}^{+}\right]_{\mathrm{o}}$ shifts were not blocked by NBQX/APV (Fig. $4 B, C ; n=47$ events from 6 cells from 6 mice), suggesting that these events occur independently on AMPA/ NMDA receptors activation (Mann-Whitney test; $p=0.007$ ). A very slow $\left[\mathrm{K}^{+}\right]_{\mathrm{o}}$ baseline shift of $1.37 \pm 0.8 \mathrm{mM}$ was consistently observed during slice perfusion with NBQX/APV and reverted in all experiments after glutamate receptor blockers washout. Previous results indicated that the 4-AP-evoked IPSCs in patched PyrNs are sensitive to the $\mathrm{GABA}_{\mathrm{A}}$ receptor antagonist, BMI (Cammarota et al., 2013). To definitely demonstrate the interneuronal origin of the above mentioned events isolated in presence of NBQX and APV, we applied BMI (50 $\mu \mathrm{M})$. Under these conditions, both the IPSCs and the associated $\left[\mathrm{K}^{+}\right]_{\mathrm{o}}$ shifts were abolished ( 3 cells from 2 mice; data not shown). These findings strongly suggest that $\mathrm{K}^{+}$changes during 4-AP treatment are induced by interneuronal inter-ictal events.

Relationship between GABAergic network events and $\left[\mathrm{K}^{+}\right]_{o}$ changes To investigate the relationship between the inter-ictal and preictal outward events and the associated $\left[\mathrm{K}^{+}\right]_{\mathrm{o}}$ shifts, we evaluated 

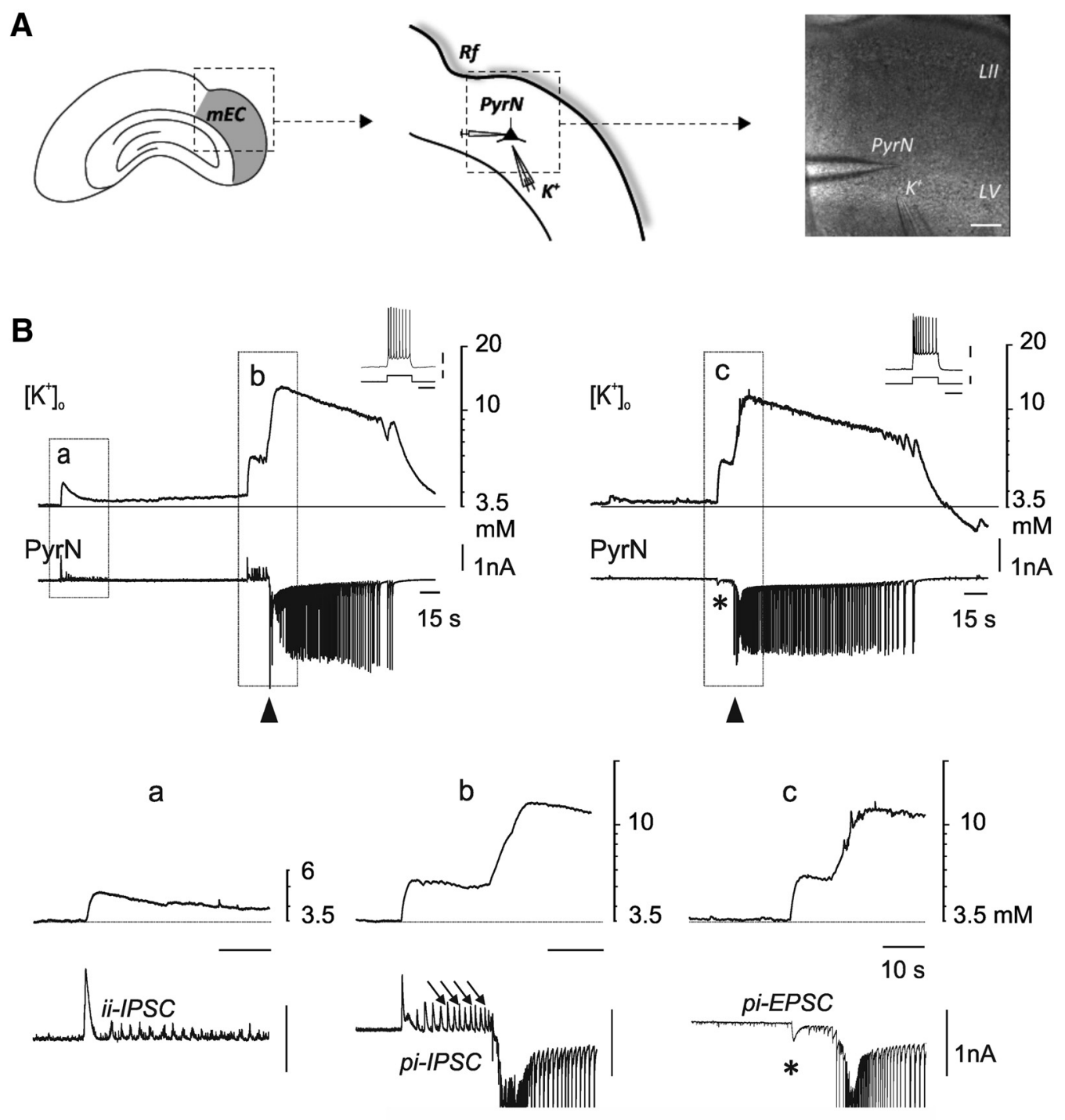

$\Delta$

Figure 1. Typical 4-AP-induced epileptiform patterns recorded in $\mathrm{mEC}$ mouse slice. A, Schematic drawing of the experimental configuration (left and middle) and differential interference contrast image of the $\mathrm{mEC}$ slice preparation (right) showing the patch pipette onto a PyrN located in layer V (LV) and the double-barreled pipette used to simultaneously record extracellular $\mathrm{K}^{+}$signals. Rf, Rhinal fissure; LII, Layer II. Calibration bar, $100 \mu \mathrm{m}$. B, Simultaneous voltage-clamp recordings of a PyrN (bottom trace) and changes in $\left[\mathrm{K}^{+}\right]_{0}$ (top trace) showing the two typical 4-AP-induced ictal events preceded either by outward (left) or by inward postsynaptic currents (right). The typical firing of the two patched PyrNs is illustrated in the insets. Calibration

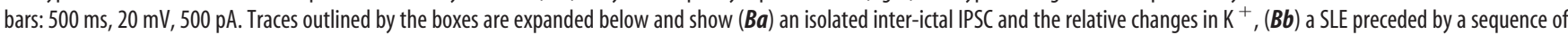
outward IPSCS (arrows), and (BC) a SLE preceded by an inward EPSC (asterisk). A sequence of inward currents (arrowhead) associated to a further increase in $\mathrm{K}^{+}$are recorded during the SLEs.
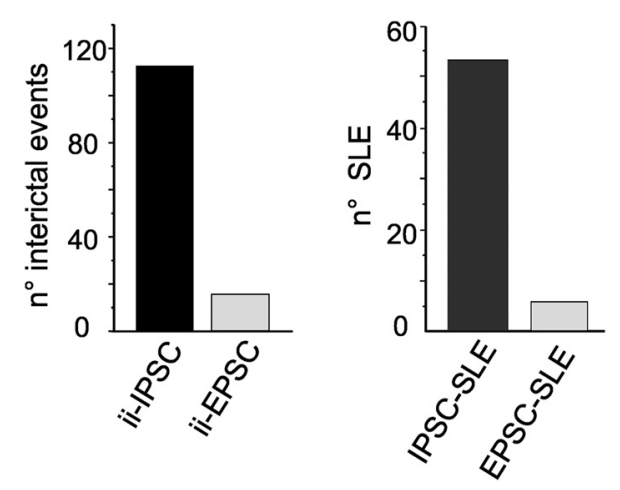

Figure 2. The number of inter-ictal IPSCS (black bar) versusinter-ictal EPSCs (gray bar) and of SLEs preceded by either outward (black bar) or inward PSCS (gray bar) recorded in 15 experiments are shown in the left and right bar histograms, respectively. the integral of the IPSCs (transferred charge) recorded in voltageclamped PyrNs and the integral of the associated $\mathrm{K}^{+}$signal curves at their maximum plateau value (cumulated $\mathrm{K}^{+}$charge; Fig. $5 A, C$, dark gray areas). The high linear correlation between these two parameters measured for inter-ictal (average $R^{2}=0.85 \pm 0.09$, 40 events from 9 cells; Fig. $5 B)$ and pre-ictal events $\left(R^{2}=0.89 \pm\right.$ $0.07,21$ events from 6 cells; Fig. $5 D$ ) showed that the amount of $\mathrm{K}^{+}$ released during these events strongly depends on the strength of interneuronal circuit activity. Specifically, a single ii-IPSC evoked a mean $\left[\mathrm{K}^{+}\right]_{\mathrm{o}}$ cumulating value of $393 \pm 314 \mathrm{pA} \times \mathrm{ms}(n=40)$, whereas a $\pi$-IPSC induced a mean $\left[\mathrm{K}^{+}\right]_{\mathrm{o}}$ rise value of $5637 \pm 3553$ $\mathrm{mV} \times \mathrm{ms}(n=25)$. Plateau $\left[\mathrm{K}^{+}\right]_{\mathrm{o}}$ rise during $\pi$-IPSC lasted $15.8 \pm$ $14.5 \mathrm{~s}(n=35)$, whereas $\left[\mathrm{K}^{+}\right]_{\mathrm{o}}$ changes associated to ii-IPSC rapidly decreased within $2 \mathrm{~s}$ after the maximum peak.

In the light of these results, we investigated the presence of a $\left[\mathrm{K}^{+}\right]_{\mathrm{o}}$ threshold value responsible for the ictal discharge genera- 
A
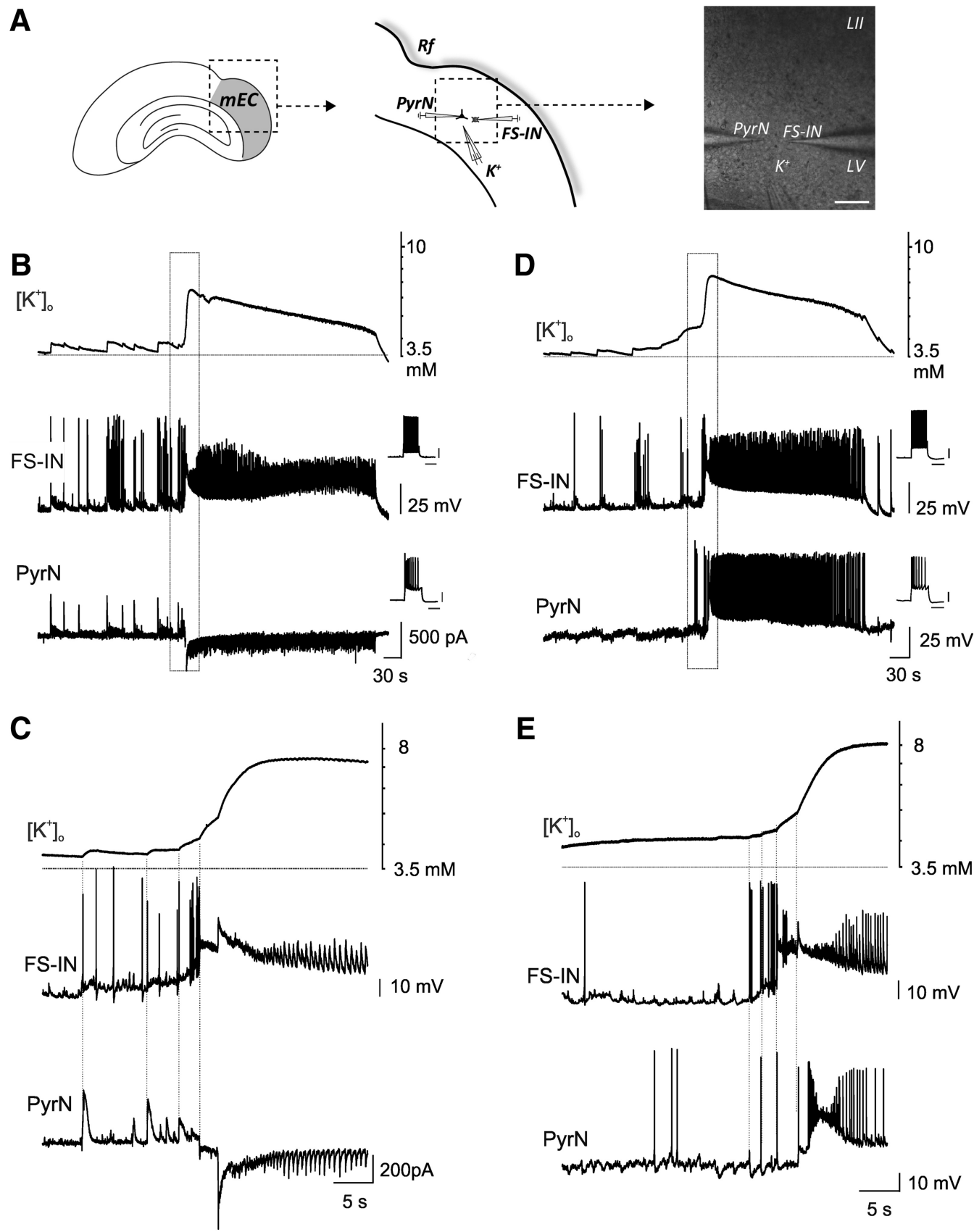

Figure 3. Double cell recordings during 4-AP-induced SLEs. A, Schematic drawing of the experimental configuration, showing the patch pipettes onto a FS-IN and principal PyrN located in mEC layer V and the double-barreled pipette used to record $\left[\mathrm{K}^{+}\right]_{0}$ signals. Rf, Rhinal fissure LII, Layer II; LV, Layer V. B, Representative current-clamp and voltage-clamp recordings from a FS-IN (middle trace) and a PyrN (lower trace) and simultaneous $\left[\mathrm{K}^{+}\right]_{0}$ shift (top trace) during a 4-AP-induced ictal discharge. Insets, The typical firing of the patched neurons. Expansion of the traces outlined by the box in $\boldsymbol{B}$ is shown in the bottom. $\boldsymbol{C}$, Vertical dotted lines mark the correlation between neuronal firing and the changes in $\mathrm{K}^{+}$. $\boldsymbol{D}$, Representative double current-clamp recordings from a FS-IN and a PyrN and simultaneous shift in $\left[\mathrm{K}^{+}\right]_{0}$ (top trace) during a 4-AP-induced ictal discharge. Expansion of the traces outlined by the box in $\boldsymbol{D}$ is illustrated in $\boldsymbol{E}$ (bottom). Inset calibration bars: $500 \mathrm{~ms}$, $500 \mathrm{pA}$.

tion. We observed progressively larger $\left[\mathrm{K}^{+}\right]_{\mathrm{o}}$ increases between ii-IPSC, $\pi$-IPSC, and ictal events that were statistically significant between the ii-IPSCs and $\pi$-IPSCs and between both and the SLE with interneuronal activity-mediated onset $\left[\mathrm{K}^{+}\right]_{\mathrm{o}}$ (Fig. $6 A$, left; Mann-Whitney test; $p=2.63 \mathrm{e}^{-5}, p=1.7 \mathrm{e}^{-24}, p=6.9 \mathrm{e}^{-10}$, respectively). Ictal events characterized by an excitatory onset also showed a significant higher $\left[\mathrm{K}^{+}\right]_{\mathrm{o}}$ compared with ii-EPSCs and $\pi$-EPSCs (Fig. $6 A$, right; Mann-Whitney test; $p=4.82 \mathrm{e}^{-4}$ and $t_{(9)}=-2.9, p=0.022$, two-sample Student $t$ test, respectively). These data demonstrate that the $\left[\mathrm{K}^{+}\right]_{\mathrm{o}}$ rise associated with epileptiform activity progressively increases from the inter- ictal to the ictal state. The amount of $\mathrm{K}^{+}$released in the extracellular space by outward ii-IPSCs $(0.68 \pm 0.44 \mathrm{~mm} n=112)$ is not sufficient to initiate SLEs; larger $(1.7 \pm 1.6 \mathrm{~mm} ; n=36)$ and sustained $\left[\mathrm{K}^{+}\right]_{\mathrm{o}}$ increases (Fig. $6 B$ ) during $\pi$-IPSCs events were observed ahead of SLEs.

We did not identify a clear $\left[\mathrm{K}^{+}\right]_{\mathrm{o}}$ threshold value for SLE generation (Fig. $6 B$ ). Therefore, we evaluated the possibility that the speed and the persistence of $\left[\mathrm{K}^{+}\right]_{\mathrm{o}}$ accumulation could both be relevant for SLE initiation. Interestingly, the analysis of the correlation between the maximum first derivative of the $\mathrm{K}^{+}$signal, representing the maximal velocity of $\left[\mathrm{K}^{+}\right]_{\mathrm{o}}$ shift (Fig. $6 C$, left 
$\mathbf{A}$

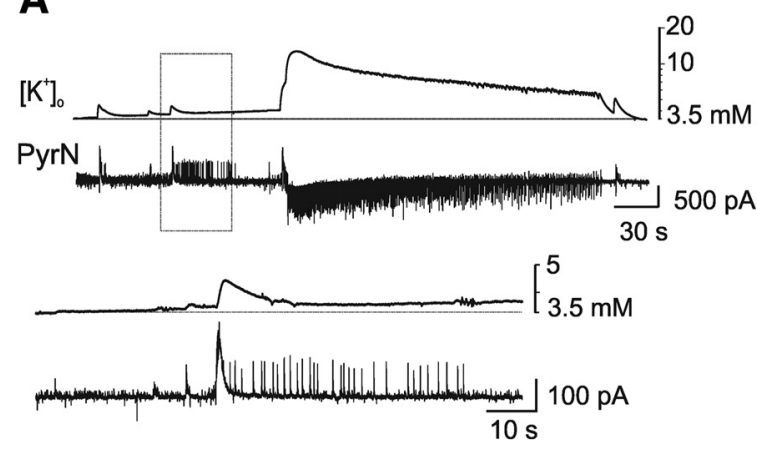

B
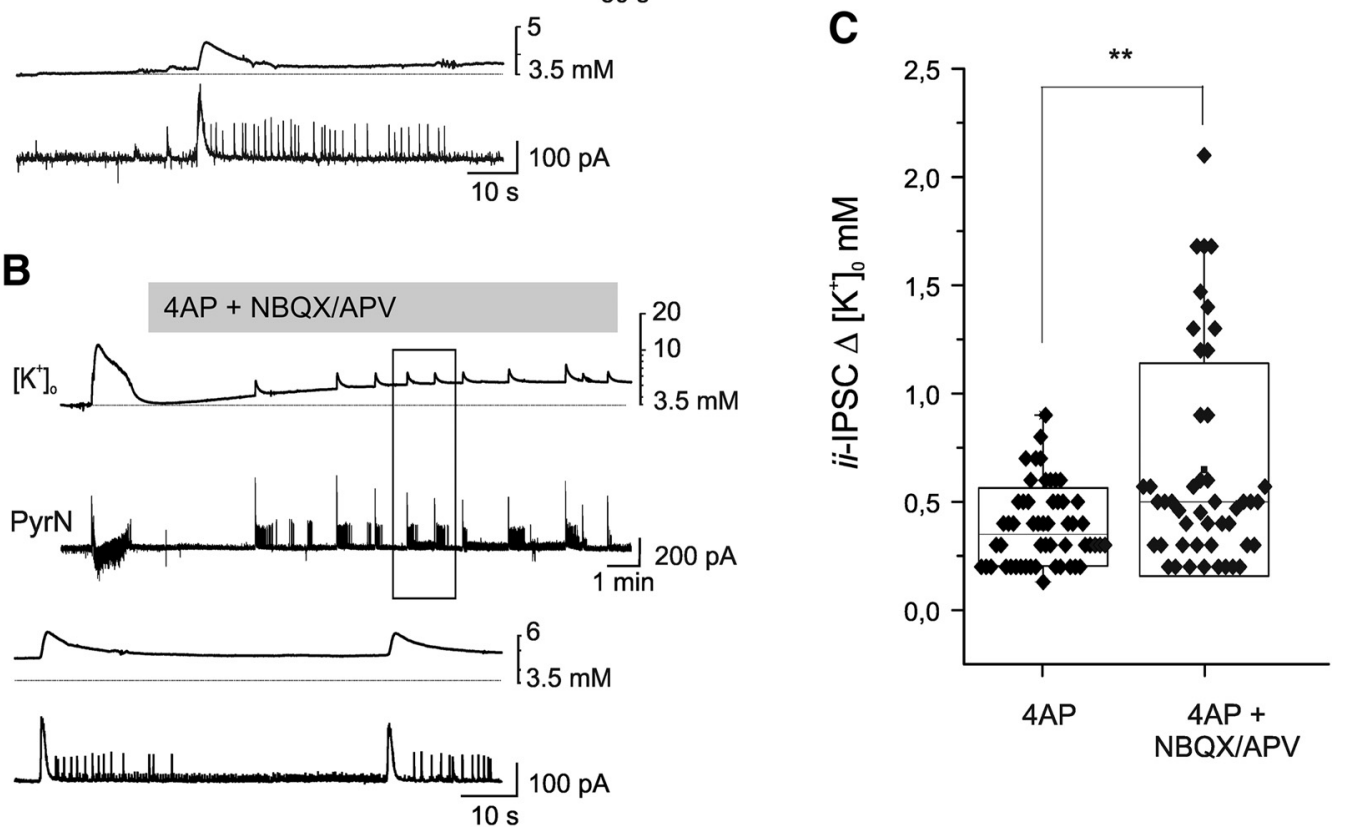

NBQX/APV

Figure 4. Effects of NMDA/AMPA receptor antagonists on 4-AP-induced SLEs. A, Representative voltage-clamp recording from a PyrN (bottom trace of the pair) and simultaneous changes in $\left[\mathrm{K}^{+}\right]_{0}$ (top trace) during a 4-AP-induced SLE characterized by interneuronal-network onset. The ii-IPSC in the box is enlarged in the bottom pair of traces. $\boldsymbol{B}$, Effect of NMDA/AMPA receptor antagonists coperfused with 4-AP (gray shaded bar) on both PyrNs activity and the associated $\left[\mathrm{K}^{+}\right]_{0}$ changes. The traces outlined by the boxes are expanded in the lower part of the panel. C, Box plot representation of the increase in $\left[\mathrm{K}^{+}\right]_{0}$ during 4-AP-(left) and 4-AP+NBQX/APV (right) treatments. Delta $\left[\mathrm{K}^{+}\right]_{0}$ represents absolute value additional to the simultaneous correspondent $\left[\mathrm{K}^{+}\right]_{0}$. The box ranges indicate the 25 th and 75 th percentile and whiskers represent SD values. Significance at Mann-Whitney test: ${ }^{* *} p<0.01$.

graph, $\mathrm{K}^{+}$slope; 9 cells from 6 mice; $t_{(10)}=-3.45, p=0.006$, paired Student $t$ test), and the time required to reach the maximal $\mathrm{K}^{+}$elevation (Fig. $6 C$, right, time to $\mathrm{K}^{+}$peak; $t_{(10)}=2.68, p=$ 0.023 , paired Student $t$ test) demonstrated that $\pi$-IPSCs $(n=11)$ reached $\mathrm{K}^{+}$peak in a shorter time in comparison with ii-IPSC $(n=43)$ events. These data suggest that the $\left[\mathrm{K}^{+}\right]_{\mathrm{o}}$ increase associated to the $\pi$-IPSCs is more abrupt and persistent compared with that of ii-IPSCs. Moreover, we observed a clear and significant separation between the cumulate $\mathrm{K}^{+}$charge values induced by ii-IPSCs compared with those induced by $\pi$-IPSCs (Fig. 6D). This result is in line with the linear relationship existing between IPSC amplitude and $\left[\mathrm{K}^{+}\right]_{\mathrm{o}}$ changes described in Figure 5.

\section{The isolated guinea pig brain preparation}

To verify whether the same phenomena are reproduced in more complex networks, we performed brief ( $4 \mathrm{~min}$ ) arterial perfusion with 4-AP $(50 \mu \mathrm{M})$ in a close-to-in vivo brain preparation (Fig. $7 A$; Uva et al., 2009, 2015). In the mEC of the isolated guinea pig brain, 4-AP-induced SLEs that were preceded by high amplitude pre-ictal spikes. Simultaneous recordings with $\mathrm{K}^{+}$-sensitive electrodes revealed that each 4 -AP-evoked population spike induced an increase in $\left[\mathrm{K}^{+}\right]_{\mathrm{o}}(0.3 \pm 0.18 \mathrm{~mm} ; n=58$ in 5 preparations; Fig. $7 C$ ). Interestingly, the high-amplitude spikes preceding the onset of SLEs correlated with a higher and longer-lasting $\left[\mathrm{K}^{+}\right]_{\mathrm{o}}$ increase $(1.7 \pm 1.1 \mathrm{~mm} ; n=18)$ compared with the preceding inter-ictal events. The progression into the SLE leaded to a further $\left[\mathrm{K}^{+}\right]_{\mathrm{o}}$ increase $(8.4 \pm 4.5 \mathrm{~mm} ; n=23)$ that reverted to basal level at the end of the SLE (Fig. 7A). At the end of the 4AP- induced seizure, perfusion with both AMPA and NMDA glutamate receptor antagonists was performed for $1 \mathrm{~h}$. Then, 4-AP was added to the perfusion solution. 4-AP-evoked inter-ictal population events were not abolished by coperfusion of 4-AP with the glutamate receptors antagonists NBQX $(50 \mu \mathrm{M})$ and APV (100 $\mu \mathrm{M}$; Fig. $7 B$, left) and the correlated $\left[\mathrm{K}^{+}\right]_{\mathrm{o}}$ shift were slightly but consistently reduced (Fig. $7 C$ ). Additional arterial application of the $\mathrm{GABA}_{\mathrm{A}}$ receptor antagonist, BMI $(50 \mu \mathrm{M})$, abolished the population spike events and the associated changes in $\left[\mathrm{K}^{+}\right]_{\mathrm{o}}$ (Fig. $7 B$, right, $C$ ).

\section{Discussion}

The paradoxical involvement of interneurons to the initial phase of an ictal discharge has been proposed in several studies based on in vitro and in vivo animal models of focal seizures and epilepsy (de Curtis and Gnatkovsky, 2009; Avoli and de Curtis, 2011; de Curtis and Avoli, 2016). In the 4-AP model, interneuron-mediated population discharges are consistently generated at a rate that consents a quantified analysis of epileptiform events. We recognize the limits of this approach: the experiments are performed in vitro and use acute pharmacological manipulations to induce SLEs. Nonetheless, this model represents the ideal experimental paradigm to evaluate the correlation between population events generated by synchronous interneuronal activity and SLE. In this specific in vitro model of ictogenesis, we demonstrate that SLEs are blocked by glutamate receptor antagonists and therefore confirm that both glutamatergic and GABAergic transmission contributes to seizure generation. We also show that in $90 \%$ of cases the onset of SLEs in the $\mathrm{mEC}$ is dominated by a GABAergic 
A
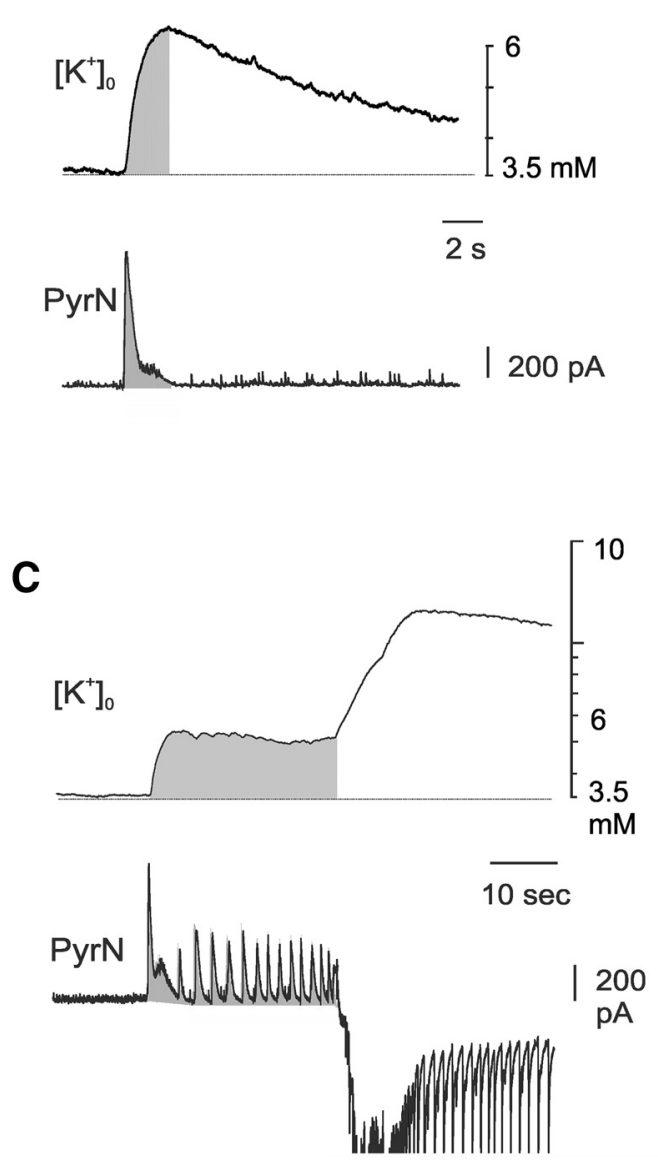

B

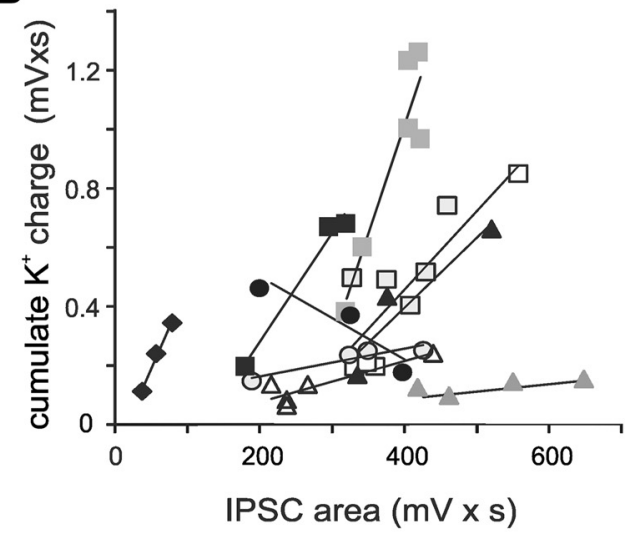

D

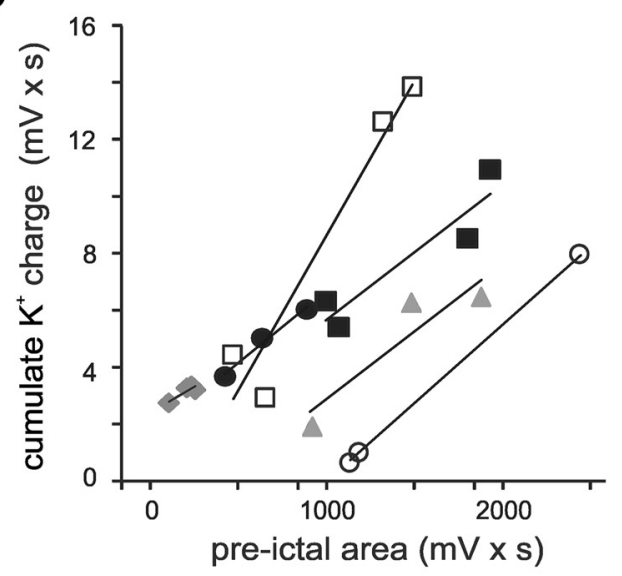

Figure 5. Correlation between IPSCs and $\left[\mathrm{K}^{+}\right]_{0}$. A, Typical 4-AP-evoked ii-IPSC recorded from a mEC PyrN (bottom trace) and the associated [K $\left.{ }^{+}\right]_{0}$ signal (top trace). The gray-shaded areas represent the ii-IPSC current charge and the relative integral of cumulative $\mathrm{K}^{+}$charge at its peak value. $\boldsymbol{B}$, Plot of the areas shaded in gray computed for different ii-IPSPs. Each symbol refers to a different PyrN. Regression lines corresponded to correlation coefficients $\left(R^{2}\right)$ values between 0.709 and 0.989 . C, Shaded areas outline $\mathrm{K}^{+}$and IPSC charge values calculated as in $\boldsymbol{A}$ for pre-ictal events. $D$, Relationship between the area of 4-AP-induced $\pi$-IPSC s and the relative cumulative $K^{+}$charge. High correlation coefficients $\left(R^{2}\right)$ included between 0.7 and 0.9 were observed in all neurons.

network activity that strictly correlates with extracellular $\mathrm{K}^{+}$elevations and evolves into a SLE. We also provide the first evidence that a sustained firing in FS-INs and the associated $\left[\mathrm{K}^{+}\right]_{\mathrm{o}}$ increase precede the PyrN involvement at the onset of a SLE, suggesting that interneuronal activity per se may be sufficient to generate a SLE. This is a relevant issue, because the notion that GABAergic networks are prominently active ahead of a seizure is now accepted (de Curtis and Avoli, 2016).

The role of $\mathrm{K}^{+}$changes induced by interneuronal signals in 4-AP-induced ictogenesis was proposed by studies performed in rat and human temporal cortex slices (Avoli et al., 1996b; Köhling et al., 1998; Lopantsev and Avoli, 1998). In human temporal lobe tissue resected from patients affected by temporal lobe epilepsy, spontaneous activity was strongly reduced during bicuculline applications (Köhling et al., 1998). In vitro studies performed on slices from human dysplastic cortex also showed that 4-AP bath applications were able to induce negative $\mathrm{GABA}_{\mathrm{A}}$ receptor-dependent field events occurring shortly before ictal discharge onset and leading to $\left[\mathrm{K}^{+}\right]_{\mathrm{o}}$ elevations (D'Antuono et al., 2004).

The participation of interneuronal networks in the initiation of 4-AP-induced ictal discharges was demonstrated by the observation that optogenetic activation of parvalbumin (PV)-positive EC interneurons induce SLEs (Sessolo et al., 2015; Shiri et al., 2015; Yekhlef et al., 2015). The study by Yekhlef et al. (2015) showed that an optogenetic activation of interneurons triggered an ictal event associated to large increases in $\left[\mathrm{K}^{+}\right]_{\mathrm{o}}$. Interestingly, $\left[\mathrm{K}^{+}\right]_{\mathrm{o}}$ elevations during pre-ictal discharges were also demonstrated for another in vitro model (Gnatkovsky et al., 2008; Trombin et al., 2011) and therefore, it is not an unique feature of the 4AP model. Our experiments add a crucial piece of evidence to this observation, by showing that FS-INs membrane potential depolarization coincided with ii-IPSCs on principal neurons and it correlated to the $\left[\mathrm{K}^{+}\right]_{\mathrm{o}}$ shifts. Both ii-IPSCs and the associated $\mathrm{K}^{+}$changes were abolished when BMI was added to the perfusion medium during glutamate receptor blockade. The recruitment of PyrN firing and the switch into large inward currents measured in voltage-clamp configuration occurred after the interneuronal network-mediated $\mathrm{K}^{+}$changes and contributed to the additional rise of extracellular $\mathrm{K}^{+}$signals associated to the switch into a full-blown SLE.

The mechanisms that link GABAergic network activation and the changes in $\left[\mathrm{K}^{+}\right]_{\mathrm{o}}$ during the transition into seizure are still undetermined. Our data show a relation between activity-dependent elevations in $\left[\mathrm{K}^{+}\right]_{\mathrm{o}}$ and SLE occurrence and progression, albeit they could not provide evidence for a causal link between these two events. Based on the $\mathrm{K}^{+}$accumulation hypothesis, a transient increase of $\mathrm{K}^{+}$triggers a massive neuronal depolarization leading to network hyperactivation and to further extracellular $\mathrm{K}^{+}$accumulations (Green, 1964; Fertziger and Ranck, 1970). According to this hypothesis it could be postulated that an increase in $\left[\mathrm{K}^{+}\right]_{\mathrm{o}}$ 
A

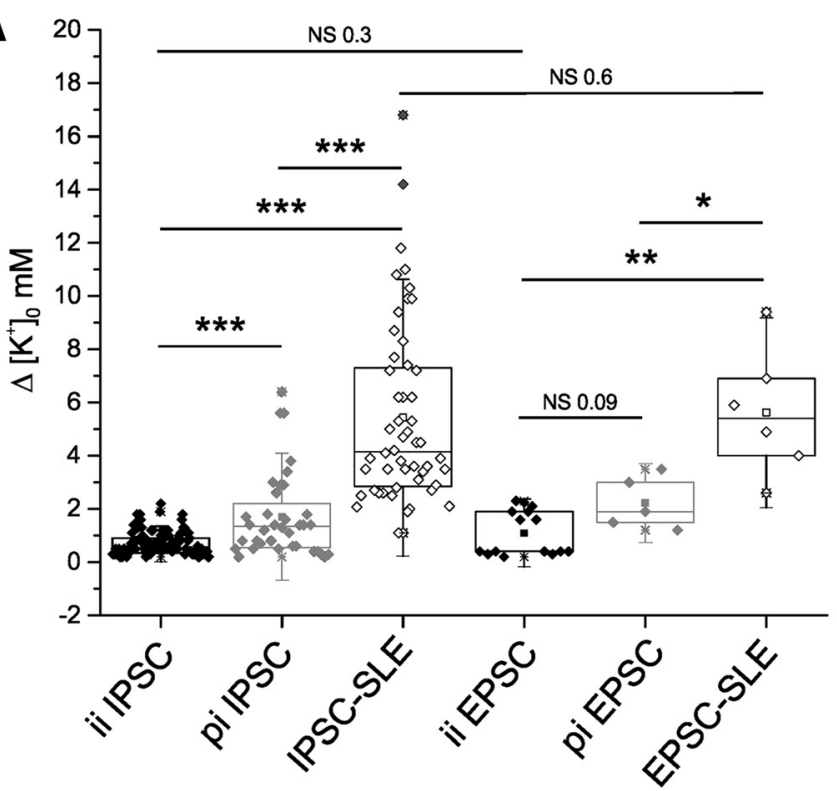

B

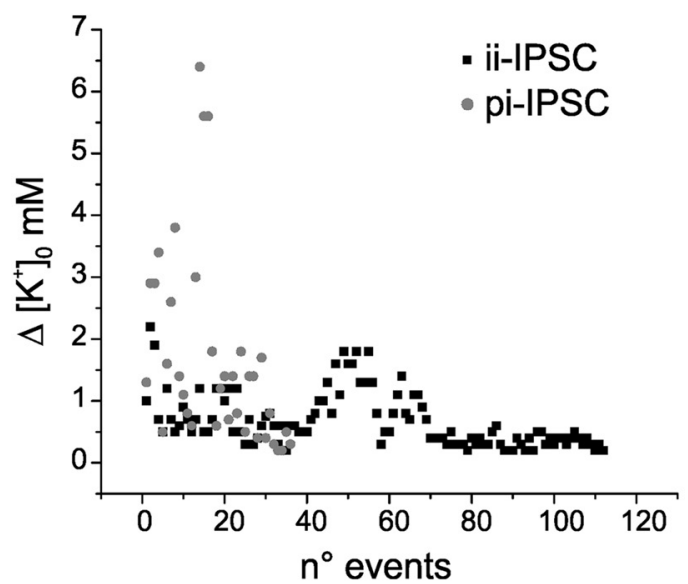

C
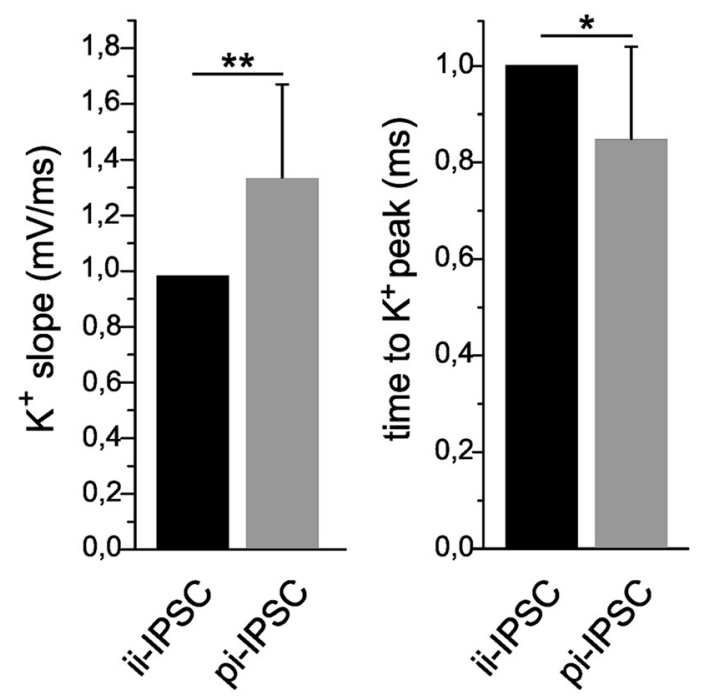

D

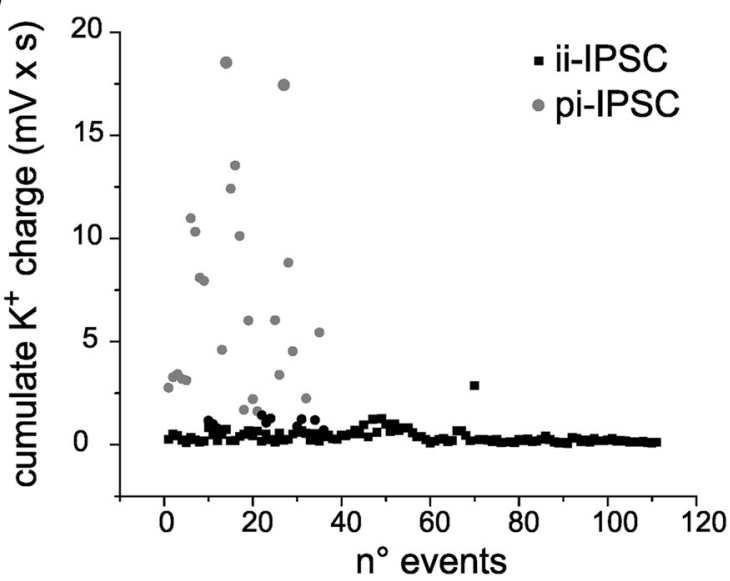

Figure 6. $\left[\mathrm{K}^{+}\right]_{0}$ changes associated to different 4-AP-induced epileptiform events. A, Box plots comparing the increase in $\left[\mathrm{K}^{+}\right]_{0}$ associated with ii-IPSC, $\pi$-IPSC, ii-EPSC, and $\pi$-EPSC) and [SLEs preceded by IPSCS ("inhibitory" onset SLE) or EPSCS (excitatory onset SLE). The box ranges indicate the 25 th and 75 th percentile and whiskers represent SD values. Significance at Mann-Whitney test: ${ }^{* *} p<0.001$ and ${ }^{* * *} p<0.0001 ; p=0.3,0.6,0.09 ;$ NS, No significance). Significance at two-sample Student $t$ test: ${ }^{*} p<0.05$. $\boldsymbol{B}$, Scar plot showing the amount of $\mathrm{K}^{+}$released in the extracellular space during 4-AP-evoked ii-IPSCs (black dots) and $\pi$-IPSCS (gray dots). $\mathrm{K}^{+}$changes induced by $\pi$-IPSCs are larger than those induced by ii-IPSCs. C, Bar histograms of the [K $\left.{ }^{+}\right]_{0}$ slope value (left) and the time required to reach the maximum peak of the $\mathrm{K}^{+}$traces (right) associated to the ii-IPSC (black columns) and pi-IPSC (gray columns) events. Data are normalized to the mean value of inter-ictal events. Significance at paired-sample Student $t$ test: ${ }^{*} p<0.05,{ }^{* *} p<0.001 . D$, Scar plot of the cumulate ${ }^{+}$charges during 4-AP-evoked ii-IPSCs (black square dots) and a pi-IPSCs (gray round dots). $\mathrm{K}^{+}$changes induced by pi-IPSCs larger and more sustained in time.

above a certain critical value should trigger an epileptic seizure. In vivo $\left[\mathrm{K}^{+}\right]_{\mathrm{o}}$ measurements failed to provide significant experimental supports (Somjen, 1979) and the idea of $\mathrm{K}^{+}$as a key element in seizure initiation was rejected. More recently, the hypothesis has been reconsidered on the basis of experimental studies performed on cortical brain slices (Heinemann and Dietzel, 1984) and of evidence derived from computational models (Somjen, 2004; Fröhlich et al., 2008). Our data demonstrated that $\pi$-PSCs events induced $\left[\mathrm{K}^{+}\right]_{\mathrm{o}}$ rises significantly higher and faster in comparison with the ones associated with ii-PSCs events. We did not identify a value of $\left[\mathrm{K}^{+}\right]_{\mathrm{o}}$ that could be identified as the threshold concentration for PyrN recruitment in SLE generation. Yet, our experimental data demonstrated a linear relationship between ii-IPSCs $/ \pi$-IPSCs amplitude and the associated $\left[\mathrm{K}^{+}\right]_{\mathrm{o}}$ cumulate charge defined as the amount of $\mathrm{K}^{+}$released in a time unit. Compared with ii-IPSCs, $\pi$-IPSCs correlated with a wider and longer-lasting release of $\mathrm{K}^{+}$and reached the extracellular $\mathrm{K}^{+}$ peak concentration in a shorter time. These data strongly suggest that enhanced $\left[\mathrm{K}^{+}\right]_{\mathrm{o}}$ elevations maintained over prolonged periods ( $>10 \mathrm{~s}$ ), such as during $\pi$-IPSCs, contribute to SLE precipitation. Interestingly, Frohlich et al. $(2008,2010)$ demonstrated in a realistic computational model of cortical network that the duration and the amplitude of a transient network perturbation are both crucial factors that contribute to the transition into a pathological hyperexcitable network state. This in silico study is consistent with the idea that the emergence of seizure-like activity requires pro-epileptic perturbations that induce rapid and longenough increases in $\left[\mathrm{K}^{+}\right]_{\mathrm{o}}$ (Fröhlich et al., 2010), such as those occurring during the pre-ictal events dependent on GABA network activation that we observed in our study.

Our findings demonstrate that SLEs preceded by IPSCs evolve into the activation of a delayed intense neuronal firing of PyrNs in the 4-AP model. The ictal discharge is composed of an initial event generated by interneuronal network activity ( $\pi$-IPSC) that 
A

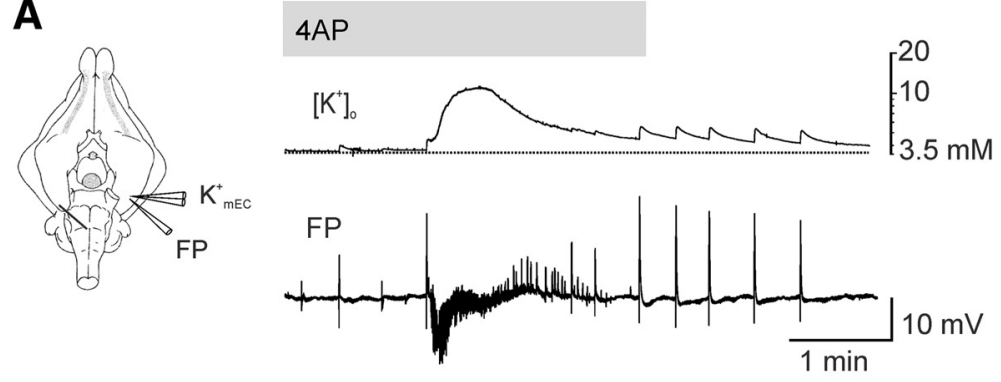

B

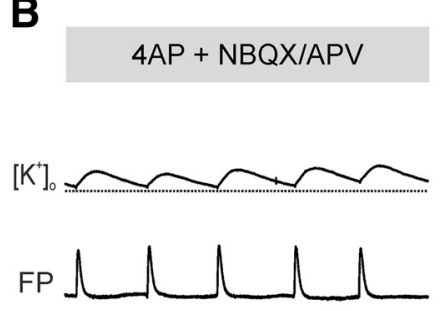

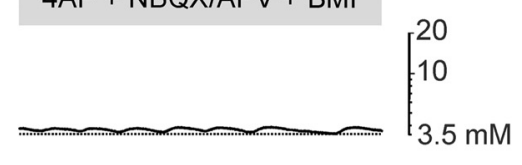

$\overbrace{}^{2} 10 \mathrm{mV}$
$4 A P+N B Q X / A P V+B M I$
C

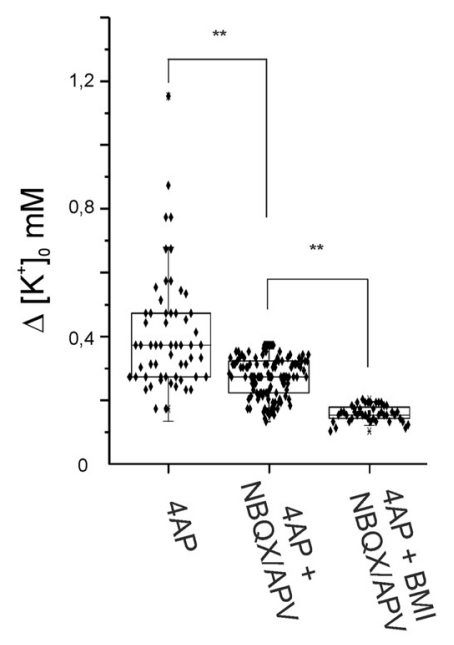

Figure 7. Typical 4-AP-induced epileptiform activity recorded in the in vitro isolated guinea pig brain. $A$, Schematic representation of the brain showing the position of the extracellular and $\mathrm{K}^{+}$-sensitive electrodes used to record simultaneous field potentials (FPs) and potassium shifts in the mEC. Inter-ictal spikes and SLE activity induced by a 4 min perfusion of 4-AP and the associated $\left[\mathrm{K}^{+}\right]_{0}$ increases are also represented. $\boldsymbol{B}$, Left, Inter-ictal events induced by a 4 min perfusion of 4-AP after $1 \mathrm{~h}$ of treatment with both NMDA and AMPA receptor antagonists (gray shaded bar). Right, Effect of the additional arterial application of $G A B A_{A}$ receptors antagonist BMI to perfusion solution on 4-AP+NBQX/APV-evoked population spike events (gray shaded bar). C, Box plot representation of the increase in $\left[\mathrm{K}^{+}\right]_{0}$ during 4-AP (left), 4-AP+NBQX/APV (middle), and 4-AP+NBQX/APV + BMI (right) treatments. Delta $\left[K^{+}\right]_{0}$ represents absolute values additional to the simultaneous correspondent $\left[\mathrm{K}^{+}\right]_{0}$. The box ranges indicate the 25 th and 75 th percentile and whiskers represent SD values. Significance at Mann-Whitney test: ${ }^{* *} p<0.001$.

elevates $\left[\mathrm{K}^{+}\right]_{\mathrm{o}}$, followed by a delayed activation of PyrNs that further increases $\left[\mathrm{K}^{+}\right]_{\mathrm{o}}$ and sustains the full-blown part of the SLE. Previous studies (Cammarota et al., 2013) showed that FS-INs fire action potentials at SLE onset and then reach a plateau of depolarization that correlates with a transient blockade of action potential generation. This transient pause of interneuronal activity (Sessolo et al., 2015) occurs during a condition of elevated $\mathrm{K}^{+}$and promotes the recruitment of PyrNs (Trombin et al., 2011) that supports seizure progression. These findings could also be interpreted as follows: synchronous interneuronal firing ahead of a SLE represents an extreme attempt of active interneuronal networks to prevent the activation of PyNs and the precipitation to SLEs. Because $90 \%$ of both inter-ictal and pre-ictal events are associated to outward IPSC in our in vitro 4-AP model, we assume that FS-IN networks is prominently activated during $\mathrm{mEC}$ ictogenesis. The pro-epileptic role of interneuronal activity in ictogenesis is not a peculiar and exclusive property of the 4-AP model (Avoli et al., 1996a; Lopantsev and Avoli, 1998; Ziburkus et al., 2006; Sessolo et al., 2015; Assaf and Schiller, 2016) and has been proposed to explain SLE generation in other acute in vitro model of hippocampal SLE. Lasztóczi et al. (2009) demonstrated that in the low- $\mathrm{Mg}^{2+}$ seizure model the GABAergic network contributes to the synchronization and recruitment of CA3 pyramidal cells at SLE onset. Depolarization block of interneurons was invoked to explain in this model the transition from a predominant inhibition into a prevalent excitatory activity (Derchansky et al., 2008; Assaf and Schiller, 2016). Interneuronal network activity was also proposed to generate SLEs in the tetanic stimulation model (Fujiwara-Tsukamoto et al., 2006, 2010). Finally, experiments on the isolated guinea pig brain in vitro demonstrated that SLEs induced by brief arterial perfusions of either BMI or 4-AP generate pre-ictal population spike activity associated with interneuronal-mediated potentials in $\mathrm{mEC}$ principal neurons, that correlates with a $1-5 \mathrm{~s}$ pause in the firing of principal cells and with an increased activity in putative interneurons (Gnatkovsky et al., 2008; Uva et al., 2015).

The limitations of the acute 4-AP seizure model should be considered. In this model, SLEs are short in duration and they do not show the clear low-voltage fast-onset pattern typically observed in chronic focal epilepsy models and in human focal epilepsies (de Curtis and Gnatkovsky, 2009; de Curtis and Avoli, 2016). Moreover, the switch from prominent interneuronal activity into principal cells excitatory recruitment is more abrupt in mEC slices than in the whole brain (Gnatkovsky et al., 2008; Uva et al., 2015). Nevertheless, the 4-AP model applied to mEC slices provides a reliable paradigm to test the hypothesis that GABAergic network activation and the consequent changes in $\left[\mathrm{K}^{+}\right]_{\mathrm{o}}$ per se are sufficient to induce a focal SLE. In addition, the high reproducibility of inter-ictal and ictal patterns in this model consents to evaluate the correlations and the mechanisms of interneuronal network-induced SLEs with details that are not otherwise achievable in vivo or in chronic epileptic conditions.

In conclusion, we show that in the 4-AP model interneuronal network activity is an important player in focal ictogenesis. The relevance of this observation for human focal epilepsy has been thoroughly discussed in previous reports (de Curtis and Gnatkovsky, 2009; Avoli et al., 2016; de Curtis and Avoli, 2016).

\section{References}

Assaf F, Schiller Y (2016) The antiepileptic and ictogenic effects of optogenetic neurostimulation of PV-expressing interneurons. J Neurophysiol 116:1694-1704. CrossRef Medline

Avoli M, de Curtis M (2011) GABAergic synchronization in the limbic system and its role in the generation of epileptiform activity. Prog Neurobiol 95:104-132. CrossRef Medline 
Avoli M, Barbarosie M, Lücke A, Nagao T, Lopantsev V, Köhling R (1996a) Synchronous GABA-mediated potentials and epileptiform discharges in the rat limbic system in vitro. J Neurosci 16:3912-3924. Medline

Avoli M, Louvel J, Kurcewicz I, Pumain R, Barbarosie M (1996b) Extracellular free potassium and calcium during synchronous activity induced by 4-aminopyridine in the juvenile rat hippocampus. J Physiol 493:707-717. CrossRef Medline

Avoli M, de Curtis M, Gnatkovsky V, Gotman J, Köhling R, Lévesque M, Manseau F, Shiri Z, Williams S (2016) Specific imbalance of excitatory/ inhibitory signaling establishes seizure onset pattern in temporal lobe epilepsy. J Neurophysiol 115:3229-3237. CrossRef Medline

Boido D, Jesuthasan N, de Curtis M, Uva L (2014) Network dynamics during the progression of seizure-like events in the hippocampal-parahippocampal regions. Cereb Cortex 24:163-173. CrossRef Medline

Cammarota M, Losi G, Chiavegato A, Zonta M, Carmignoto G (2013) Fast spiking interneuron control of seizure propagation in a cortical slice model of focal epilepsy. J Physiol 591:807-822. CrossRef Medline

D’Antuono M, Louvel J, Köhling R, Mattia D, Bernasconi A, Olivier A, Turak B, Devaux A, Pumain R, Avoli M (2004) GABAA receptor-dependent synchronization leads to ictogenesis in the human dysplastic cortex. Brain 127:1626-1640. CrossRef Medline

de Curtis M, Avoli M (2016) GABAergic networks jump-start focal seizures. Epilepsia 57:679-687. CrossRef Medline

de Curtis M, Gnatkovsky V (2009) Reevaluating the mechanisms of focal ictogenesis: the role of low-voltage fast activity. Epilepsia 50:2514-2525. CrossRef Medline

de Curtis M, Paré D, Llinás RR (1991) The electrophysiology of the olfactoryhippocampal circuit in the isolated and perfused adult mammalian brain in vitro. Hippocampus 1:341-354. CrossRef

de Curtis M, Biella G, Buccellati C, Folco G (1998) Simultaneous investigation of the neuronal and vascular compartments in the guinea pig brain isolated in vitro. Brain Res Brain Res Protoc 3:221-228. CrossRef Medline

Derchansky M, Jahromi SS, Mamani M, Shin DS, Sik A, Carlen PL (2008) Transition to seizures in the isolated immature mouse hippocampus: a switch from dominant phasic inhibition to dominant phasic excitation. J Physiol 586:477-494. CrossRef Medline

Dugué GP, Dumoulin A, Triller A, Dieudonné S (2005) Target-dependent use of coreleased inhibitory transmitters at central synapses. J Neurosci 25:6490-6498. CrossRef Medline

Fertziger AP, Ranck JB Jr (1970) Potassium accumulation in interstitial space during epileptiform seizures. Exp Neurol 26:571-585. CrossRef Medline

Freund TF, Katona I (2007) Perisomatic inhibition. Neuron 56:33-42. CrossRef Medline

Fröhlich F, Bazhenov M, Iragui-Madoz V, Sejnowski TJ (2008) Potassium dynamics in the epileptic cortex: new insights on an old topic. Neuroscientist 14:422-433. CrossRef Medline

Fröhlich F, Sejnowski TJ, Bazhenov M (2010) Network bistability mediates spontaneous transitions between normal and pathological brain states. J Neurosci 30:10734-10743. CrossRef Medline

Fujita S, Toyoda I, Thamattoor AK, Buckmaster PS (2014) Preictal activity of subicular, CA1, and dentate gyrus principal neurons in the dorsal hippocampus before spontaneous seizures in a rat model of temporal lobe epilepsy. J Neurosci 34:16671-16687. CrossRef Medline

Fujiwara-Tsukamoto Y, Isomura Y, Takada M (2006) Comparable GABAergic mechanisms of hippocampal seizurelike activity in posttetanic and low-Mg2 + conditions. J Neurophysiol 95:2013-2019. CrossRef Medline

Fujiwara-Tsukamoto Y, Isomura Y, Imanishi M, Ninomiya T, Tsukada M, Yanagawa Y, Fukai T, Takada M (2010) Prototypic seizure activity driven by mature hippocampal fast-spiking interneurons. J Neurosci 30: 13679-13689. CrossRef Medline

Gnatkovsky V, Librizzi L, Trombin F, de Curtis M (2008) Fast activity at seizure onset is mediated by inhibitory circuits in the entorhinal cortex in vitro. Ann Neurol 64:674-686. CrossRef Medline

Grasse DW, Karunakaran S, Moxon KA (2013) Neuronal synchrony and the transition to spontaneous seizures. Exp Neurol 248:72-84. CrossRef Medline

Green JD (1964) The hippocampus. Physiol Rev 44:561-608. Medline

Heinemann U, Dietzel I (1984) Extracellular potassium concentration in chronic alumina cream foci of cats. J Neurophysiol 52:421-434. Medline Imamura H, Matsumoto R, Inouchi M, Matsuhashi M, Mikuni N, Takahashi
R, Ikeda A (2011) Ictal wideband ECoG: direct comparison between ictal slow shifts and high frequency oscillations. Clin Neurophysiol 122: 1500-1504. CrossRef Medline

Köhling R, Lücke A, Straub H, Speckmann EJ, Tuxhorn I, Wolf P, Pannek H, Oppel F (1998) Spontaneous sharp waves in human neocortical slices excised from epileptic patients. Brain 121:1073-1087. CrossRef Medline

Lasztóczi B, Nyitrai G, Héja L, Kardos J (2009) Synchronization of GABAergic inputs to CA3 pyramidal cells precedes seizure-like event onset in juvenile rat hippocampal slices. J Neurophysiol 102:2538-2553. CrossRef Medline

Librizzi L, Janigro D, De Biasi S, de Curtis M (2001) Blood- brain barrier preservation in the in vitro isolated guinea-pig brain preparation. J Neurosci Res 66:289-297. CrossRef Medline

Librizzi L, Losi L, Carmignoto G, de Curtis M (2016) Focal 4-aminopyridine-induced seizure-like events initiated by inhibitory network activity induce $\left[\mathrm{K}^{+}\right]_{0}$ increase, but are not dependent on KCC2 channels. XII European Congress on Epileptology, Praha.

Lopantsev V, Avoli M (1998) Participation of GABAA-mediated inhibition in ictallike discharges in the rat entorhinal cortex. J Neurophysiol 79:352360. Medline

Mühlethaler M, de Curtis M, Walton K, Llinás R (1993) The isolated and perfused brain of the guinea-pig in vitro. Eur J Neurosci 5:915-926. CrossRef Medline

Sessolo M, Marcon I, Bovetti S, Losi G, Cammarota M, Ratto GM, Fellin T, Carmignoto G (2015) Parvalbumin-positive inhibitory interneurons oppose propagation but favor generation of focal epileptiform activity. J Neurosci 35:9544-9557. CrossRef Medline

Shiri Z, Manseau F, Lévesque M, Williams S, Avoli M (2015) Interneuron activity leads to initiation of low-voltage fast-onset seizures. Ann Neurol 77:541-546. CrossRef Medline

Shiri Z, Manseau F, Lévesque M, Williams S, Avoli M (2016) Activation of specific neuronal networks leads to different seizure onset types. Ann Neurol 79:354-365. CrossRef Medline

Smith EH, Schevon CA (2016) Toward a mechanistic understanding of epileptic networks. Curr Neurol Neurosci Rep 16:97. CrossRef Medline

Somjen G (2004) Ions in the brain. New York: Oxford UP.

Somjen GG (1979) Extracellular potassium in the mammalian central nervous system. Annu Rev Physiol 41:159-177. CrossRef Medline

Toyoda I, Fujita S, Thamattoor AK, Buckmaster PS (2015) Unit activity of hippocampal interneurons before spontaneous seizures in an animal model of temporal lobe epilepsy. J Neurosci 35:6600-6618. CrossRef Medline

Trevelyan AJ, Sussillo D, Yuste R (2007) Feedforward inhibition contributes to the control of epileptiform propagation speed. J Neurosci 27:33833387. CrossRef Medline

Trombin F, Gnatkovsky V, de Curtis M (2011) Changes in action potential features during focal seizure discharges in the entorhinal cortex of the in vitro isolated guinea pig brain. J Neurophysiol 106:1411-1423. CrossRef Medline

Truccolo W, Donoghue JA, Hochberg LR, Eskandar EN, Madsen JR, Anderson WS, Brown EN, Halgren E, Cash SS (2011) Single-neuron dynamics in human focal epilepsy. Nat Neurosci 14:635-641. CrossRef Medline

Uva L, Avoli M, de Curtis M (2009) Synchronous GABAA-receptor-dependent potentials in limbic areas of the in-vitro isolated adult guinea pig brain. Eur J Neurosci 29:911-920. CrossRef Medline

Uva L, Breschi GL, Gnatkovsky V, Taverna S, de Curtis M (2015) Synchronous inhibitory potentials precede seizure-like events in acute models of focal limbic seizures. J Neurosci 35:3048-3055. CrossRef Medline

Weiss SA, Banks GP, McKhann GM Jr, Goodman RR, Emerson RG, Trevelyan AJ, Schevon CA (2013) Ictal high frequency oscillations distinguish two types of seizure territories in humans. Brain 136:3796-3808. CrossRef Medline

Weiss SA, Alvarado-Rojas C, Bragin A, Behnke E, Fields T, Fried I, Engel J Jr, Staba R (2016) Ictal onset patterns of local field potentials, high frequency oscillations, and unit activity in human mesial temporal lobe epilepsy. Epilepsia 57:111-121. CrossRef Medline

Yekhlef L, Breschi GL, Lagostena L, Russo G, Taverna S (2015) Selective activation of parvalbumin- or somatostatin-expressing interneurons triggers epileptic seizurelike activity in mouse medial entorhinal cortex. J Neurophysiol 113:1616-1630. CrossRef Medline

Ziburkus J, Cressman JR, Barreto E, Schiff SJ (2006) Interneuron and pyramidal cell interplay during in vitro seizure-like events. J Neurophysiol 95:3948-3954. CrossRef Medline 